\title{
Prognostication in Different Heart Failure Phenotypes: The Role of Circulating Biomarkers
}

\author{
Review Article
}

\author{
Alexander E. Berezin ${ }^{1 *}$ \\ 1 State Medical University, Zaporozhye, Ukraine \\ *Corresponding author(s) E-mail: dr_berezin@mail.ru \\ Received 06 November 2015; Accepted 02 March 2016
}

DOI: $10.5772 / 62797$

(c) 2016 Author(s). Licensee InTech. This is an open access article distributed under the terms of the Creative Commons Attribution License (http://creativecommons.org/licenses/by/3.0), which permits unrestricted use, distribution, and reproduction in any medium, provided the original work is properly cited.

\begin{abstract}
Heart failure (HF) is multifactorial syndrome with high cardiovascular $(\mathrm{CV})$ morbidity and mortality rates associated with an increasing prevalence worldwide. Measuring plasma levels of circulating biomarkers, i.e., natriuretic peptides, cardiac-specific troponins, metabolomic intermediates, Galectin-3, ST2, cardiotrophin-1, soluble endoglin and growth differentiation factor 15, may assist in the prognostication of HF development. However, the role of biomarker models in the prediction of an early stage of $\mathrm{HF}$ with a preserved ejection fraction (HFpEF) and HF with a reduced ejection fraction (HFrEF) is not still understood. This review explores the knowledge regarding the utility of cardiac biomarkers, aiming to reclassify patients with different phenotypes of HF. The review reports that several biomarkers reflected on subsequently alter collagen turnover, cardiac fibrosis and inflammation, which might have diagnostic and predictive value in HFpEF and HFrEF. The best candidates for determining the early stage of HF development were sST2, Galectin-3, CT-1 and GDF-15. However, increased plasma concentrations of these biomarkers were not specific to a distinct disease group of HFpEF and HFrEF. Finally, more investigations are
\end{abstract}

required to determine the role of novel biomarkers in the prediction of $\mathrm{HF}$ and the determination of the early stages of HFpEF and HFrEF development.

Keywords Heart Failure Phenotypes, Biomarkers, Prognostication, Risk Stratification

\author{
Abbreviations \\ $\mathrm{BNP}$ - brain natriuretic peptide \\ $\mathrm{CAD}$ - coronary artery disease \\ CABG - coronary artery bypass grafting \\ GDF - growth differentiation factor \\ CT-1 - cardiotrophin-1 \\ $\mathrm{CV}$ - cardiovascular \\ $\mathrm{HF}$ - heart failure
}

HFpEF - heart failure with preserved ejection fraction HFrEF - heart failure with reduced ejection fraction LV left ventricle

PCI - percutant coronary angioplasty procedure 


\section{Introduction}

Heart failure (HF) remains an important clinical entity that has increased in prevalence worldwide due to improved survival after a HF diagnosis [1, 2]. Recent studies have shown sufficient differences in the aetiology, pathophysiology, clinical presentation and outcomes, as well as the prognosis, between HF with a preserved ejection fraction (HFpEF) and HF with a reduced ejection fraction (HFrEF) [3-5].

HFpEF is a phenotypic and heterogeneous clinical syndrome characterized by cardiovascular (CV) disease and dysmetabolic and inflammatory states associated with both advanced age and various non-CV co-morbidities, which finally lead to the impairment of myocardial structure and function, unless under the condition of declining global EF $<45 \%[6,7]$. Although global left ventricular EF $>50 \%$ is currently used to differentiate between reduced and preserved cardiac pump function, this cut-off point is widely discussed as a likely inadequate criterion $[8,9]$ However, old age, being female, suffering from diabetes mellitus, hypertension, atrial fibrillation and chronic kidney disease are strong predictors of HFpEF's development [10-12]. Based on evidence from endomyocardial biopsies, some of the specific cardiac structural phenotypes to be targeted in HFpEF may be represented by myocyte hypertrophy and interstitial fibrosis [13, 14]. HFrEF has been described as a disease of aged elderly subjects, with a male predominance that is frequently associated with dilation cardiomyopathy, ischaemia, inflammatory and diabetic aetiology, and rarely with arterial and pulmonary hypertension [15, 16]. Cell loss due to ischaemia, apoptosis and necrosis, myocardial inflammation associated with oxidative stress, expanded interstitial fibrosis leading to the disintegrity of the cardiac wall, increased passive myocardial stiffness, the worsening of cardiac configuration and contractile function are common in HFrEF's development [17].

Many questions remain unanswered regarding differences in the molecular signals that initiate the development of HFpEF and HFrEF [18]. In this context, it might be possible to appropriately stratify at risk HFpEF and HFrEF patients by using biomarkers. Recently, brain natriuretic peptides, cardiac specific troponins, metabolomic intermediates, Galectin-3, ST2, cardiotrophin-1, soluble endoglin, growth differentiation factor 15 and other new biological markers associated with HF's development have been widely investigated $[5,6,12,13,17,19]$. However, the current data on the interrelationship of these biomarkers and phenotypes of HF are limited. The aim of the review is devoted to the accumulation of knowledge regarding the utility of cardiac biomarkers, aiming to reclassify patients with different phenotypes of HF.

\section{Biomarkers in HF Risk Stratification}

The routine use of biomarkers might help to stratify the patients with HFrEF and HFpEF at higher risk of death and clinical outcomes. The current guidelines - the 2012 European Society of Cardiology (ESC) Guidelines for the Diagnosis and Treatment of Acute and Chronic Heart Failure and the 2013 American College of Cardiology Foundation/American Heart Association (ACCF/AHA) Guideline for the Management of Heart Failure - are well accepted by many clinicians regarding HFrEF's prognostication. Indeed, HFpEF is the one that really requires the improvement of biomarkers for diagnosis and prognosis. In this context, many biological markers, which reflect several faces of the pathogenesis of $\mathrm{HF}$, have been investigated in detail, but only natriuretic peptides, soluble ST2, Galectin-3 and highly sensitive cardiac-specific troponins have been validated thus far. Table 1 offers summarized evidence regarding the predictive role of biomarkers in patients with different HF phenotypes.

\section{Brain Natriuretic Peptides}

Within the last two decades, cardiac natriuretic peptides (BNP and NT-proBNP) have been defined as biomarkers that we may use to screen for LV systolic dysfunction in patients with symptoms suggestive of HF. BNP and NTproBNP are now included in the current guidelines for HF diagnosis, management and risk assessment because of their high specificity and sensitivity [19]. Despite BNP and NT-proBNP improving discrimination modestly for HF above and beyond conventional risk factors, and substantially improving the risk classification for $\mathrm{HF}$, peak concentrations of BNP and NT-proBNP and serial measurements of NT-proBNP levels in longitude are not able to allow the differentiation of HF phenotypes [20, 21]. However, there were important differences in the prognostic value of NT-proBNP in HFpEF versus HFrEF in the NT- proBNP-guided arm of the TIME-CHF study [22]. NTproBNP has demonstrated less prognostic value in HFpEF as compared to HFrEF, and has not predicted a development of HFpEF or HFrEF. NT-proBNP lost significance as a risk stratifier in ambulatory patients with stable HF and probably also in those who have HFpEF. There are attampts to use of sing sample measurement of mid-regional atrial natriuretic peptide (mr-ANP) and NT-proANP in order to screen HFpEF and HFrEF in individuals, when the diagnosis of HF is not obvious. In this setting, the diagnostic value and prognostic ability for HF-related mortality and CV hospitalization for both mr-ANP and NT-proANP were not superior to those of NT-proBNP [23].

\section{Cardiac Troponins}

Recent studies have shown that elevated levels of highly sensitive cardiac troponin I (hs-cTnI) and T (hs-cTnT) as biomarkers of subclinical myocardial injury may provide to be clinically useful prognostic information, concerning both the future risk of HF's manifestation in asymptomatic subjects and the risk of fatal events and primary/readmissions in the hospital in those with already established symptomatic acute, acutely decompensated and chronic 


\begin{tabular}{|c|c|c|c|}
\hline Biomarkers & Patient population & The most important findings & References \\
\hline \multirow[t]{2}{*}{ Natriuretic peptides } & Exerted dyspnoea & $\begin{array}{l}\text { Predictor of HF risk manifestation, risk of admission in } \\
\text { the hospital and HF-related deaths }\end{array}$ & [19] \\
\hline & Known HFpEF and HFrEF & $\begin{array}{l}\text { Biomarkers independently predicted HF-related } \\
\text { outcomes, CV mortality, all-cause death, admission in } \\
\text { the hospital, but they did not predict a development of } \\
\text { HFpEF or HFrEF }\end{array}$ & {$[19,20,21]$} \\
\hline \multirow[t]{2}{*}{ Cardiac troponins } & Ischaemia-induced HF & $\begin{array}{l}\text { Predictors of HF manifestation risk in asymptomatic } \\
\text { subjects } \\
\text { Predictors of death in HFpEF and HFrEF }\end{array}$ & {$[24,25]$} \\
\hline & $\begin{array}{l}\text { Ischaemia-induced and non- } \\
\text { ischaemia-related HF }\end{array}$ & $\begin{array}{l}\text { Predictors of death, primary/re-admissions in the } \\
\text { hospital }\end{array}$ & [25-27] \\
\hline \multirow[t]{2}{*}{ Galectin-3 } & General population & Prognosticator of HF risk, risk of death from any cause & [33] \\
\hline & Known HF patients & $\begin{array}{l}\text { Predictor of CV death, HF-related deaths, primary and } \\
\text { re-admission in the hospital }\end{array}$ & [35-37] \\
\hline \multirow[t]{2}{*}{ Soluble ST2 } & General population & $\begin{array}{l}\text { Predictor of higher risk of all-cause mortality, HF } \\
\text { manifestation }\end{array}$ & [42] \\
\hline & Known HF patients & $\begin{array}{l}\text { Independent predictor of } \mathrm{CV} \text { deaths, HF-related deaths, } \\
\text { admission in the hospital }\end{array}$ & [44] \\
\hline Cardiotrophin-1 & $\begin{array}{l}\text { Known ischaemia-induced HF } \\
\text { patients }\end{array}$ & Predictor of CV clinical outcomes & {$[53,54]$} \\
\hline Endoglin & Patients at higher risk of $\mathrm{CV}$ disease & Predictor of CV events/ outcomes, HF manifestation & [58-60] \\
\hline \multirow[t]{2}{*}{ Growth differentiation factor 15} & Patients with known CV disease & Predictor of HF manifestation & {$[64,65]$} \\
\hline & Known HF patients & Predictor of HF-related outcomes & [68] \\
\hline
\end{tabular}

Abbreviation: CV, cardiovascular; HF, heart failure; HFpEF, HF with preserved ejection fraction; HFrEF, HF with reduced ejection fraction.

Table 1. Predictive role of biomarkers in patients with different HF phenotypes

stable HF related to ischaemic and non-ischaemic causes [24-27]. Moreover, cardiac troponin mutations are considered a cause of impaired relaxation in the mutant cardiac myocytes due to myofibril hypersensitivity to $\mathrm{Ca}^{2+}[28]$.

Cardiac-specific troponins exhibited the strongest associations with hospitalization, survival and outcomes in cases of HF; there are expectations regarding the ability of troponins to emerge as an aetiology-dependent relation to phenotypes of HF. Seliger et al. [29] hypothesized that hscTnT would identify HF risk among older adults with left ventricular hypertrophy (LVH). In the Cardiovascular Health Study, its authors found that the adjusted risk of HFrEF was 7.8 times higher among those with the highest tertile of hs-cTnT and LVH (HR=7.83; 95\% CI: 4.43-13.83). Patients with LVH and longitudinal increases in hs-cTnT or NT-proBNP were approximately three times more likely to develop HF (primarily HFrEF), compared with those without LVH and with stable biomarkers. Thus, in this study, the authors were not able to find sufficient advantages regarding hs-cTnT compared NT-proBNP in order to characterize sub-phenotypes of HF. In another study, Neeland et al. [30] reported that identifying a malignant sub-phenotype of LVH was the better predictive surrogate marker than a limited elevated level of hs-cTnT, and even increased NT-proBNP among asymptomatic individuals with a high risk of progression to $\mathrm{HF}$ and $\mathrm{CV}$ death in the general population. Therefore, there was evidence that the higher levels of cTnT and NT-proBNP correlated well with the risk of $\mathrm{HF}$ in older adults, but were not associated with phenotypes of HF [31]. Overall, the circulating level of the cell injury biomarker is not a powerful tool for HF-phenotype detection.

\section{Systematic Metabolomic Biomarkers}

Zordoky et al. [32] suggested that a systematic metabolomic analysis would reveal a novel metabolomic fingerprint of HFpEF that will help us to understand its pathophysiology and assist us in establishing new biomarkers for its diagnosis. Compared to non-HF control, HFpEF patients demonstrated higher serum concentrations of acylcarnitines, carnitine, creatinine, betaine and amino acids, and lower levels of phosphatidylcholines, lysophosphatidylcholines and sphingomyelins. Medium- and long-chain acylcarnitines and ketone bodies were higher in HFpEF than in HFrEF patients. The authors suggested that this abovementioned metabolomic fingerprint has been utilized to identify two novel panels of metabolites that can separate HFpEF patients from both non-HF controls and HFrEF patients. However, this assumption requires further investigation. 


\subsection{Galectin-3}

It has been suggested that various alternative biomarkers might offer insight into the different pathways of HF's pathophysiology, and that they might help to identify individuals in the general population at higher risk of developing HF and patients with known chronic HF with poor outcomes [33]. Galectin-3 is a soluble beta galactosidebinding lectin produced by activated macrophages that bind and activate the fibroblasts [34]. Currently, Galectin-3 is considered a biomarker that mediates an important link between inflammation and fibrosis, which plays a pivotal role in CV remodelling. The pathogenetic role of Galectin-3 in the various settings of pressure overload, neuroendocrine activation, hypertension, coronary artery disease/myocardial infarction, atrial fibrillation and $\mathrm{HF}$ has been established.

Galectin-3 has emerged as a predictive value for the onset of HF in apparently healthy patients and has been found to be a surrogate marker of a worse prognosis, mortality and re-admission in $\mathrm{HF}[35,36]$. However, serial measurements of Galectin-3 levels in ambulatory HF patients might not be of benefit [37].

In the context of determining the different phenotypes of $\mathrm{HF}$, the measurement of circulating Galectin-3 might have a significant value because elevated levels of Galectin-3 were found in patients with impaired LV diastolic function, but without symptomatic HF [38]. Gurel et al. [39] reported that Galectin-3 could be a promising biomarker for the detection of LV diastolic dysfunction in patients undergoing maintenance haemodialysis. It has been suggested that this biomarker could be a useful surrogate for structural and functional abnormality of the myocardium among individuals at higher risk of HFpEF development, especially that associated with hypertension, coronary artery disease and diabetes [40,41]. However, there is no irrefutable evidence regarding the clinically significant advantages of Galectin-3 in predicting HFpEF's evolution compared with HFrEF's development.

\section{$5.2 S T 2$}

Soluble ST2 (sST2), a peptide belonging to the interleukin-1 receptor family, is secreted by cardiomyocytes and cardiac fibroblasts under mechanical strain, and is thus regarded as a biomarker of myocardial fibrosis, cardiac stretching and CV remodelling [42, 43]. Measurement of sST2 levels is useful for death risk stratification and prognosis prediction in HF patients, beyond other CV risk factors [44]. The sST2 concentration showed a weak correlation with the NYHA functional class, LFEF, other cardiac performances and renal function $[45,46]$. Recent studies have shown that sST2 may have a special superiority as a risk predictor in HFpEF and HFrEF as compared with natriuretic peptides and Galectin-3 $[47,48]$. However, there are no current data on the predictive value of sST2 concentrations for HFpEF or HFrEF development.

\subsection{Cardiotrophin-1}

Cardiotrophin-1 (CT-1) is a member of the interleukin 6 cytokine superfamily and one of the endogenous ligands for gp130 signalling pathways in the heart, with controversial biological effects. CT-1 is able to induce hypertrophic growth and contractile dysfunction in cardiomyocytes, as well as having potent hypertrophic and survival effects on cardiac myocytes [49]. CT-1 is closely associated with many $\mathrm{CV}$ diseases, i.e., hypertension, myocardial infarction and $\mathrm{HF}$, and exhibits a cardioprotective effect in ischaemiareperfusion injury during CABG and angioplasty [50]. Recent clinical studies have shown that CT-1 levels are increased in HF patients, and that it is significantly correlated with the LV mass index, suggesting that CT-1 plays an important role in structural LV remodelling [51, 52]. Increased cardiotrophin-1 plasma levels might predict the presence of an inappropriate LV mass merge in hypertensive subjects [53], and the development and progression of HF [54]. Moreover, CT-1 is elevated in patients with HFpEF and is associated with NT-proBNP and estimated LV filling pressures [55]. Whether increased serum CT-1 may provide additional information to aid risk stratification in the development of HFrEF or HFpEF is not completely clear.

\subsection{Soluble endoglin}

Endoglin (also known as CD105) is a membrane co-receptor for transforming growth factor- $\beta$, which is released into the circulation in a soluble form and which disrupts TGF $\beta 1$ signalling in the endothelium, thereby promoting inflammation, endothelial dysfunction, cardiac fibrosis and vascular remodelling [56, 57]. Endoglin is required for vascular barrier function, endothelial survival and homeostasis of the adult microvasculature, although endoglin is expressed in cardiac fibroblasts and may modulate profibrogenic actions of angiotensin II [58]. A recent clinical study has revealed that the expression of endoglin is increased in patients with atherosclerosis and that the endoglin level is thought to predict CV events in patients with chronic coronary artery disease after PCI [59]. There is evidence regarding the predictive role of elevated serum endoglin in patients with pre-eclampsia [60]. In patients with HFrEF, elevated soluble endoglin levels predicted elevated LV end-diastolic pressures, and correlated well with the New York Heart Association class, irrespective of LVEF, as well as with both atrial and brain natriuretic peptides $[56,61]$. The ability of soluble endoglin in prediction of HFpEF and HFrEF is not understood, while there are expectations regarding the role of this biomarker for prognostication in LV dysfunction at early onset. However, extended scrutiny is required to receive more information for testing this assumption.

\subsection{Growth differentiation factor 15}

Growth differentiation factor 15 (GDF-15) is a stressresponsive cytokine, which belongs to the super family of 
the transforming growth factor beta [62]. GDF-15 is widely presented in the wide spectrum of various cells and plays a pivotal role in inflammation, cell growth and differentiation. Elevated GDF-15 was found in patients with established CV diseases (hypertension, stable coronary artery disease, acute coronary syndrome, myocardial infarction, ischaemic and non-ischaemic-induced cardiomyopathies, HF, atrial fibrillation), type-two diabetes mellitus, chronic renal disease, infection and liver cirrhosis and malignancy [63].

Recent studies have revealed that GDF-15 was associated with the NYHA class, NT-proBNP and exercise capacity, suggesting that the marker has diagnostic and potentially prognostic value in HF [64-66]. It has been suggested that GDF-15 might categorize HFrEF and predict major HFrelated clinical outcomes [67]. Chan et al. [68] reported that the plasma levels of GDF15 in HFpEF and HFrEF were similar. Therefore, there was an independent verification of the prognostic utility of GDF15 in HFrEF and HFrEF. The authors have shown that GDF15 was a significant independent predictor for composite outcome, even after adjusting for important clinical predictors including hsTnT and NT-proBNP [68]. Overall, GDF15 was not able to assist in detecting the early stage of HFpEF, and this biomarker has produced very limited evidence regarding the determination of diastolic dysfunction.

\section{Conclusion}

Several reports have shown that biomarkers reflecting the differentiation of fibroblasts into myofibroblasts, subsequently altering collagen turnover, cardiac fibrosis and inflammation, might have diagnostic and predictive value in HFpEF and HFrEF. The biomarkers with most predictive value in determining the early stage of HF's development were sST2, Galectin-3, CT-1 and GDF-15. However, increased plasma concentrations of these biomarkers were not specific for a distinct disease group of HFpEF and HFrEF. Finally, more investigations are required to determine the role of novel biomarkers in predicting HF and the determination of the early stage of HFpEF and HFrEF's development.

\section{Conflict of Interest}

The Authors declare no conflict of interest.

\section{Acknowledgements}

This article received no specific grant from any funding agency in the public, commercial, or not-for-profit sectors.

\section{References}

[1] Go AS, Mozaffarian D, Roger VL, Benjamin EJ, Berry JD, Blaha MJ, et al. Heart disease and stroke statistics - 2014 update: a report from the Ameri- can Heart Association. Circulation. 2014; 129(3): e28-e292

[2] Dunlay SM, Roger VL. Understanding the epidemic of heart failure: past, present, and future. Curr Heart Fail Rep. 2014; 11(4): 404-15.

[3] Meta-analysis Global Group in Chronic Heart Failure (MAGGIC). The survival of patients with heart failure with preserved or reduced left ventricular ejection fraction: an individual patient data meta-analysis. Eur Heart J. 2012; 33(14): 1750-7.

[4] Borlaug BA, Paulus WJ. Heart failure with preserved ejection fraction: pathophysiology, diagnosis, and treatment. Eur Heart J. 2011; 32(6): 670-9.

[5] Wang J, Li Z, Chen J, Zhao H, Luo L, Chen C, et al. Metabolomic identification of diagnostic plasma biomarkers in humans with chronic heart failure. Mol Biosyst. 2013; 9(11): 2618-26.

[6] Lekavich CL, Barksdale DJ, Neelon V, Wu JR. Heart failure preserved ejection fraction (HFpEF): an integrated and strategic review. Heart Fail Rev. 2015; 20(6): 643-53.

[7] Mavrea AM, Dragomir T, Bordejevic DA, Tomescu MC, Ancusa O, Marincu I. Causes and predictors of hospital readmissions in patients older than 65 years hospitalized for heart failure with preserved left ventricular ejection fraction in western Romania. Clin Interv Aging. 2015; 10: 979-90.

[8] Ueda T, Kawakami R, Nishida T, Onoue K, Soeda $\mathrm{T}$, Okayama $\mathrm{S}$, et al. Left ventricular ejection fraction (EF) of $55 \%$ as cutoff for late transition from heart failure (HF) with preserved EF to HF with mildly reduced EF. Circ J. 2015; 79(10): 2209-15.

[9] Goto T, Wakami K, Fukuta H, Fujita H, Tani T, Ohte N. Patients with left ventricular ejection fraction greater than $58 \%$ have fewer incidences of future acute decompensated heart failure admission and all-cause mortality. Heart Vessels. 2015 [Epub ahead of print]

[10] Desta L, Jernberg T, Spaak J, Hofman-Bang C, Persson $\mathrm{H}$. Heart failure with normal ejection fraction is uncommon in acute myocardial infarction settings but associated with poor outcomes: a study of 91360 patients admitted with index myocardial infarction between 1998 and 2010. Eur J Heart Fail. 2015. doi: 10.1002/ejhf.416. [Epub ahead of print]

[11] Yancy CW, Jessup M, Bozkurt B, Butler J, Casey DE Jr., Drazner MH, et al. 2013 ACCF/AHA guideline for the management of heart failure: a report of the American College of Cardiology Foundation/ American Heart Association Task Force on Practice Guidelines. J Am Coll Cardiol. 2013; 62(16): e147e239.

[12] Zile MR, Baicu CF. Biomarkers of diastolic dysfunction and myocardial fibrosis: application to heart 
failure with a preserved ejection fraction. J Cardiovasc Transl Res. 2013; 6(4): 501-15.

[13] D'Elia E, Vaduganathan M, Gori M, Gavazzi A, Butler J, Senni M. Role of biomarkers in cardiac structure phenotyping in heart failure with preserved ejection fraction: critical appraisal and practical use. Eur J Heart Fail. 2015. doi: 10.1002/ ejhf.430. [Epub ahead of print]

[14] Kenchaiah S, Vasan RS. Heart Failure in Women Insights from the Framingham Heart Study. Cardiovasc Drugs Ther. 2015; 29(4): 377-90.

[15] Kristensen SL, Køber L, Jhund PS, Solomon SD, Kjekshus J, McKelvie RS, et al. International geographic variation in event rates in trials of heart failure with preserved and reduced ejection fraction. Circulation. 2015; 131(1): 43-53.

[16] Rosenkranz S, Gibbs JS, Wachter R, De Marco T, Vonk-Noordegraaf A, Vachiéry JL. Left ventricular heart failure and pulmonary hypertension. Eur Heart J. 2015. pii: ehv512. [Epub ahead of print]

[17] Wilcox JE, Fonarow GC, Ardehali H, Bonow RO, Butler J, Sauer AJ, et al. "Targeting the heart" in heart failure: myocardial recovery in heart failure with reduced ejection fraction. JACC Heart Fail. 2015; 3(9): 661-9.

[18] Katz AM, Rolett EL. Heart failure: when form fails to follow function. Eur Heart J. 2015 pii: ehv548. [Epub ahead of print]

[19] Beltrami M, Palazzuoli A, Ruocco G, Aspromonte $\mathrm{N}$. The predictive value of plasma biomarkers in discharged heart failure patients: the role of plasma BNP. Minerva Cardioangiol. 2015 [Epub ahead of print]

[20] de Lemos JA, McGuire DK, Drazner MH. B-type natriuretic peptide in cardiovascular disease. Lancet. 2003; 362: 316-22

[21] Gaggin HK, Januzzi JL Jr. Natriuretic peptides in heart failure and acute coronary syndrome. Clin Lab Med. 2014; 34(1): 43-58.

[22] Sanders-van Wijk S, van Empel V, Davarzani N, Maeder MT, Handschin R, Pfisterer ME, et al. TIMECHF investigators. Circulating biomarkers of distinct pathophysiological pathways in heart failure with preserved vs. reduced left ventricular ejection fraction. Eur J Heart Fail. 2015; 17(10): 1006 14.

[23] Veien KT1, Jensen JK, Hildebrandt P, Gøtze JP, Nielsen OW, Køber L. Natriuretic peptides as cardiac markers in clinical practice. Ugeskr Laeger. 2010; 172(30): 2111-6.

[24] Omland T, Røsjø H, Giannitsis E, Agewall S. Troponins in heart failure. Clin Chim Acta. 2015; 443:78-84

[25] Sherwi N, Pellicori P, Joseph AC, Buga L. Old and newer biomarkers in heart failure: from patho- physiology to clinical significance. J Cardiovasc Med (Hagerstown). 2013; 14(10): 690-7.

[26] Miller WL, Hartman KA, Burritt MF, Grill DE, Jaffe AS. Profiles of serial changes in cardiac troponin T concentrations and outcome in ambulatory patients with chronic heart failure. J Am Coll Cardiol. 2009; 54(18): 1715-21.

[27] Vorovich E, French B, Ky B, Goldberg L, Fang JC, Sweitzer NK, et al. Biomarker predictors of cardiac hospitalization in chronic heart failure: a recurrent event analysis. J Card Fail. 2014; 20(8): 569-76.

[28] Li Y, Zhang L, Jean-Charles PY, Nan C, Chen G, Tian $\mathrm{J}$, et al. Dose-dependent diastolic dysfunction and early death in a mouse model with cardiac troponin mutations. J Mol Cell Cardiol. 2013; 62: 227-36.

[29] Seliger SL, de Lemos J, Neeland IJ, Christenson R, Gottdiener J, Drazner $\mathrm{MH}$, et al. Older adults, "malignant" left ventricular hypertrophy, and associated cardiac-specific biomarker phenotypes to identify the differential risk of new-onset reduced versus preserved ejection fraction heart failure: CHS (cardiovascular health study). JACC Heart Fail. 2015; 3(6): 445-55.

[30] . Neeland IJ, Drazner MH, Berry JD, Ayers CR, deFilippi C, Seliger SL, et al. Biomarkers of chronic cardiac injury and hemodynamic stress identify a malignant phenotype of left ventricular hypertrophy in the general population. J Am Coll Cardiol. 2013; 61(2):187-95. doi: 10.1016/j.jacc.2012.10.012. Epub 2012.

[31] deFilippi CR, de Lemos JA, Tkaczuk AT, Christenson RH, Carnethon MR, Siscovick DS, et al. Physical activity, change in biomarkers of myocardial stress and injury, and subsequent heart failure risk in older adults. J Am Coll Cardiol. 2012; 60(24): 2539_ 47.

[32] Zordoky BN, Sung MM, Ezekowitz J, Mandal R, Han B, Bjorndahl TC, et al. Alberta HEART. Metabolomic fingerprint of heart failure with preserved ejection fraction. PLoS One. 2015; 10(5): e0124844.

[33] Sherwi N, Pellicori P, Joseph AC, Buga L. Old and newer biomarkers in heart failure: from pathophysiology to clinical significance. J Cardiovasc Med (Hagerstown). 2013; 14(10): 690-7.

[34] Lala RI, Puschita M, Darabantiu D, Pilat L. Galectin-3 in heart failure pathology - "another brick in the wall"? Acta Cardiol. 2015; 70(3): 323-31.

[35] Leone M, Iacoviello $M$. The predictive value of plasma biomarkers in discharged heart failure patients: role of galectin-3. Minerva Cardioangiol. 2015 [Epub ahead of print]

[36] Shah KS, Maisel AS. Novel biomarkers in heart failure with preserved ejection fraction. Heart Fail Clin. 2014; 10(3): 471-9. 
[37] Miller WL, Saenger AK, Grill DE, Slusser JP, BayesGenis A, Jaffe AS. Prognostic value of serial measurements of soluble suppression of tumorigenicity 2 and galectin- 3 in ambulatory patients with chronic heart failure. J Card Fail. 2015 doi: 10.1016/j.cardfail. 2015.07.017. [Epub ahead of print]

[38] Lepojärvi ES, Piira OP, Pääkkö E, Lammentausta E, Risteli J, Miettinen JA, et al. Serum PINP, PIIINP, galectin-3, and ST2 as surrogates of myocardial fibrosis and echocardiographic left venticular diastolic filling properties. Front Physiol. 2015; 6: 200.

[39] Gurel OM, Yilmaz H, Celik TH, Cakmak M, Namuslu M, Bilgiç AM, et al. Galectin-3 as a new biomarker of diastolic dysfunction in hemodialysis patients. Herz. 2015; 40(5): 788-94.

[40] Yu X, Sun Y, Zhao Y, Zhang W, Yang Z, Gao Y, et al. Prognostic value of plasma galectin-3 levels in patients with coronary heart disease and chronic heart failure. Int Heart J. 2015; 56(3): 314-8.

[41] Gruson D, Ferracin B, Ahn SA, Rousseau MF. Comparison of fibroblast growth factor 23, soluble ST2 and Galectin-3 for prognostication of cardiovascular death in heart failure patients. Int J Cardiol. 2015; 189: 185-7.

[42] de Boer RA, Daniels LB, Maisel AS, Januzzi JL Jr. State of the Art: Newer biomarkers in heart failure. Eur J Heart Fail. 2015; 17(6): 559-69.

[43] Lupu S, Agoston-Coldea L. Soluble ST2 in ventricular dysfunction. Adv Clin Chem. 2015; 69: 139-59.

[44] Zhang R, Zhang Y, An T, Guo X, Yin S, Wang Y, et al. Prognostic value of sST2 and galectin-3 for death relative to renal function in patients hospitalized for heart failure. Biomark Med. 2015; 9(5): 433-41.

[45] Quick S, Waessnig NK, Kandler N, Poitz DM, Schoen S, Ibrahim K, et al. Soluble ST2 and myocardial fibrosis in 3T cardiac magnetic resonance. Scand Cardiovasc J. 2015; 49(6): 361-6.

[46] Kim MS, Jeong TD, Han SB, Min WK, Kim JJ. Role of soluble ST2 as a prognostic marker in patients with acute heart failure and renal insufficiency. J Korean Med Sci. 2015; 30(5): 569-75.

[47] Yao HC, Li XY, Han QF, Wang LH, Liu T, Zhou YH, et al. Elevated serum soluble ST2 levels may predict the fatal outcomes in patients with chronic heart failure. Int J Cardiol. 2015; 186: 303-4.

[48] Zhou H, Ni J, Yuan Y, Deng W, Bian ZY, Tang QZ. Soluble ST2 may possess special superiority as a risk predictor in heart failure patients. Int J Cardiol. 2015; 186: 146-7.

[49] Ravassa S, Beloqui O, Varo N, Barba J, Lopez B, Beaumont J, Zalba G, Diez J, Gonzalez A.Association of cardiotrophin-1 with left ventricular systolic properties in asymptomatic hypertensive patients. J Hypertension. 2013; 31: 587-594.
[50] Caliskan S, Besli F, Yildirim A, Gungoren F, Alisir MF, Polat U, et al. The relationship between Cardiotrophin-1 and Troponin-I in coronary arterial bypass grafting on the beating heart: a prospective study. Heart Surg Forum. 2015; 18(4): E146-50.

[51] Tsutamoto T, Wada A, Maeda K, Mabuchi N, Hayashi M, Tsutsui T, et al. Relationship between plasma level of cardiotrophin-1 and left ventricular mass index in patients with dilated cardiomyopathy. J Am Coll Cardiol. 2001; 38(5): 1485-90.

[52] Jougasaki M, Tachibana I, Luchner A, Leskinen H, Redfield MM, Burnett JC Jr. Augmented cardiac cardiotrophin-1 in experimental congestive heart failure. Circulation. 2000; 101(1): 14-7.

[53] López B, Castellano JM, González A, Barba J, Díez J. Association of increased plasma cardiotrophin-1 with inappropriate left ventricular mass in essential hypertension. Hypertension. 2007; 50(5): 977-83.

[54] López B, González A, Querejeta R, Barba J, Díez J. Association of plasma cardiotrophin-1 with stage $C$ heart failure in hypertensive patients: potential diagnostic implications. J Hypertens. 2009; 27(2): 418-24.

[55] Celik A, Sahin S, Koc F, Karayakali M, Sahin M, Benli I, et al. Cardiotrophin-1 plasma levels are increased in patients with diastolic heart failure. Med Sci Monit. 2012; 18(1): CR25-31.

[56] Kapur NK, Wilson S, Yunis AA, Qiao X, Mackey E, Paruchuri $\mathrm{V}$, et al. Reduced endoglin activity limits cardiac fibrosis and improves survival in heart failure. Circulation. 2012; 125(22): 2728-38.

[57] Heffernan KS1, Kuvin JT, Patel AR, Karas RH, Kapur NK. Endothelial function and soluble endoglin in smokers with heart failure. Clin Cardiol. 2011; 34(12):729-33.

[58] Chen K, Mehta JL, Li D, Joseph L, Joseph J. Transforming growth factor beta receptor endoglin is expressed in cardiac fibroblasts and modulates profibrogenic actions of angiotensin II. Circ Res. 2004; 95: 1167-1173

[59] Ikemoto T, Hojo Y, Kondo H, Takahashi N, Hirose $\mathrm{M}$, Nishimura $\mathrm{Y}$, et al. Plasma endoglin as a marker to predict cardiovascular events in patients with chronic coronary artery diseases. Heart Vessels. 2012; 27(4): 344-51.

[60] Bills VL, Varet J, Millar A, Harper SJ, Soothill PW, Bates DO. Failure to up-regulate VEGF165b in maternal plasma is a first trimester predictive marker for pre-eclampsia. Clin Sci (Lond). 2009; 116(3): 265-72.

[61] Kapur NK, Heffernan KS, Yunis AA, Parpos P, Kiernan MS, Sahasrabudhe NA, et al. Usefulness of soluble endoglin as a noninvasive measure of left 
ventricular filling pressure in heart failure. Am J Cardiology. 2010; 106(12): 1770-1776.

[62] Berezin AE. Diabetes mellitus related biomarker: the predictive role of growth- differentiation factor-15. Diabetes Metab Syndr. 2015. doi: 10.1016/ j.dsx.2015.09.016. [Epub ahead of print]

[63] Adela R, Banerjee SK. GDF-15 as a target and biomarker for diabetes and cardiovascular diseases: a translational prospective. J Diabetes Res. 2015; 2015: 490842.

[64] Eindhoven JA, van den Bosch AE, Oemrawsingh RM, Baggen VJ, Kardys I, Cuypers JA, et al. Release of growth-differentiation factor 15 and associations with cardiac function in adult patients with congenital heart disease. Int J Cardiol. 2015; 202: 246251.

[65] Cotter G, Voors AA, Prescott MF, Felker GM, Filippatos G, Greenberg BH, et al. Growth differen- tiation factor 15 (GDF-15) in patients admitted for acute heart failure: results from the RELAX-AHF study. Eur J Heart Fail. 2015. doi: 10.1002/ejhf.331. [Epub ahead of print]

[66] Zhu ZD, Sun T. Association between growth differentiation factor-15 and chronic heart failure in coronary atherosclerosis patients. Genet Mol Res. 2015; 14(1): 2225-33.

[67] Sinning C, Zengin E, Zeller T, Schnabel RB, Blankenberg S, Westermann D. Candidate biomarkers in heart failure with reduced and preserved ejection fraction. Biomarkers. 2015; 20(4): 258-65.

[68] Chan MM, Santhanakrishnan R, Chong JP, Chen Z, Tai BC, Liew OW, et al. Growth differentiation factor 15 in heart failure with preserved vs. reduced ejection fraction. Eur J Heart Fail. 2015. doi: 10.1002/ ejhf.431. [Epub ahead of print] 